\title{
Testicular mitochondrial alterations in untreated streptozotocin-induced diabetic rats
}

\author{
Sandra Amaral a , Paula C. Mota ${ }^{a}$, Beatriz Lacerda ${ }^{a}$, Marco Alves ${ }^{a}$, Maria de Lourdes Pereira ${ }^{\mathrm{b}}$, \\ Paulo J. Oliveira ${ }^{\mathrm{a}}$, João Ramalho-Santos ${ }^{\mathrm{a}, *}$ \\ ${ }^{a}$ Center for Neuroscience and Cell Biology, Department of Zoology, Faculty of Sciences and Technology, University of Coimbra, 3004-517 Coimbra, Portugal \\ ${ }^{\mathrm{b}}$ Department of Biology/CICECO, University of Aveiro, Campus Universitario de Santiago, 3810-193 Aveiro, Portugal
}

\section{A R T I C L E I N F O}

\section{Article history:}

Received 4 August 2008

Received in revised form 23 October 2008

Accepted 21 November 2008

Available online 7 December 2008

\section{Keywords:}

Type 1 diabetes

Rat

Streptozotocin-induced diabetes

Testis

Spermatogenesis

Reproduction

\begin{abstract}
A B S T R A C T
Diabetes-induced complications are associated with mitochondrial dysfunction and increasing evidence suggests that diabetes has an adverse effect on male reproductive function. The STZ-induced diabetic rat was used as an animal model for the type 1 form of the disease with the aim of determining its effects in spermatogenesis and testicular mitochondrial function. Several aspects of mitochondrial function were measured, including respiratory and electric potential function, as well as mitochondrial calcium loading capacity. Additionally oxidative stress production, antioxidant levels and possible apoptotic alterations were also evaluated. We observed that diabetic animals present alterations in spermatogenesis in both the testis and epidydimus. However, and surprisingly, the overall results in mitochondrial parameters failed to reveal severe testicular mitochondrial dysfunction in diabetic animals, with the exception of a decrease in calcium load. Taken together, results suggest that in animal models that mimic untreated type 1 diabetes the severe effects of the condition on spermatogenesis are not directly mitochondrialmediated.
\end{abstract}

(c) 2008 Elsevier B.V. and Mitochondria Research Society. All rights reserved.

\section{Introduction}

Diabetes mellitus (DM), a condition of chronic hyperglycemia, represents one of the greatest concerns to modern global health (WHO, 2002). According to the WHO, the most common forms of diabetes mellitus are types 1 and 2 diabetes (Tuomi, 2005). Both types are well-recognized causes of male sexual dysfunction and affects male reproductive function, both in men and animal models, at multiple levels, including the endocrine control of spermatogenesis, spermatogenesis itself or by impairing penile erection and ejaculation (Sexton and Jarow, 1997; Rehman et al., 2001; Musicki and Burnett, 2007). Diabetes is usually accompanied by increased production of free radicals or impaired antioxidant defences (Ceriello, 2003; Maritim et al., 2003; Ahmed, 2005). Mitochondria are the principal source of ROS in cells and impairement of mitochondrial function is intrinsically related to diabetes (Brownlee, 2001; Rolo and Palmeira, 2006). Additionally, there are indications that the onset and severity of diabetes is influenced by mitochondrial deficiencies or dysfunction (Scheffler, 2001; Gerbitz et al., 1995).

Mitochondrial function is also crucial for germ cells during the course of spermatogenesis (Meinhardt et al., 1999) and it has been proposed that ROS are a common mediator of several pathologies that are currently thought to afflict the reproductive function

\footnotetext{
* Corresponding author. Tel.: +351 239855 760; fax: +351 239855789 .

E-mail address: jramalho@ci.uc.pt (J. Ramalho-Santos).
}

(Agarwal et al., 2003) and that mitochondrial function is impaired in infertility (Nakada et al., 2006; Amaral et al., 2008). It has already been demonstrated that spermatozoa containing defective mitochondria not only produce ATP in a less efficient way, but also generate higher oxidative stress, leading to a decline in fertility. (Wei and Kao, 2000).

Type 1 diabetes, shows an abrupt onset at an early age and accounts for $10 \%$ of all cases of diabetes. It is caused by autoimmune destruction of pancreatic beta-cells requiring daily insulin replacement therapy, in addition to diet and physical activity. (Berdanier, 2001; Malaisse, 1983; Engelgau and Geiss, 2000; Emilien et al., 1999). Untreated type 1 diabetes is characterized by hyperglycemia, hypoinsulinemia, ketonuria, and hyperlipidaemia, resulting from a general metabolic failure (Emilien et al., 1999). Considering that this type of diabetes is growing by $3 \%$ annually in European children, being diagnosed mainly in early childhood (EURODIAB, 2000), over the next 10 years this will result in a 50\% augment in prevalence (Silink, 2002), and as a consequence diabetes will affect many more men prior to and during reproductive years (Agbaje et al., 2007). A number of reports examining the effects of type 1 diabetes on reproductive function, both in humans and animal models, are available (Agbaje et al., 2007; Sacarano et al., 2006; Amaral et al., 2006; Soudamani et al., 2005; Hassan et al., 1993; Baccetti et al., 2002).

Our previous observations (Amaral et al., 2006) have shown decreased sperm concentration and motility, as well as reduced ATP 
levels in the testicular cells of a rat model that mimics the symptoms normally associated with type 1 diabetes. These rats are produced using streptozotocin (STZ), a compound that destroys betacells.

Considering the impact of mitochondrial impairment on both diabetes and reproductive function, and since no studies are available regarding mitochondrial testicular function in diabetic individuals, it was pertinent to investigate the possible mitochondrial effects of type 1 diabetes in the testis. Our aim was thus to compare the bioenergetics of isolated rat testicular mitochondria in control and STZ-induced diabetic rats, as a model for untreated type 1 diabetes, and also possible redox and apoptotic alterations. Additionally, a histological characterization of diabetic testicular tissue was performed in order to clarify the effects of diabetes on spermatogenesis.

\section{Material and methods}

\subsection{Materials}

All chemicals were obtained from Sigma, St. Louis, MO, USA, unless otherwise stated.

\subsection{Animals}

\subsubsection{Induction and characterization of STZ-Induced diabetes}

To understand the physiological and pathological changes of complex diseases, animal models are important research tools, allowing a tight control over experimental conditions, which is almost impossible to achieve in human populations (Rodrigues et al., 1999; McIntosh and Pederson, 1999). In the present study we have used STZ-induced diabetic rats, that are obtained after selective destruction of beta-cells by streptozotocin (STZ), a broad spectrum antibiotic with diabetogenic effects. STZ-injected rats present many characteristics seen in insulin-dependent diabetic human patients: hypoinsulinemia, hyperglycemia, ketonuria, and hyperlipidaemia (Rodrigues et al., 1999). Therefore, this model is of great use to evaluate the changes promoted by uncontrolled type 1 diabetes.

Male Wistar rats weighting about $200 \mathrm{~g}$ (2 months old) were randomly divided into two groups. In order to induce diabetes, one group was injected intraperitoneally with a single injection of streptozotocin (STZ, $50 \mathrm{mg} / \mathrm{kg}$ ), after a 16-h fasting period. The volume used was always $0.5 \mathrm{ml} / 200 \mathrm{~g}$ body weight. Streptozotocin [2-deoxy-2-(3-methyl-3-nitrosurea) 1-D-glucopyranose] was prepared prior to use in $100 \mathrm{mM}$ citrate, $\mathrm{pH}$ 4.5. In the following $24 \mathrm{~h}$, animals were orally fed with glycosilated serum in order to avoid hypoglycemia resulting from massive destruction of betacells and release of intracellular insulin associated with STZ treatment (Rodrigues et al., 1999). Animals were kept for 3 months ( $n=12$ ) before the experiments, with no mortality observed. During this period glycemia was determined from the tail vein, using a commercial glucometer (Glucometer-Elite, Bayer). Values were taken in fasting conditions just before STZ administration and in non-fasting conditions in the following weeks. If feeding blood glucose in the tail vein exceeded $250 \mathrm{mg} / \mathrm{dl}$, animals were considered diabetic and used as such as actually happened with all injected animals in this particular project. No treatment was provided. Control animals were non-diabetic male Wistar rats of similar age (5 months, $n=12$ ), sham injected with the same volume of citrate solution. Animals were kept under controlled light (12-h day/night cycle), temperature $\left(22-24^{\circ} \mathrm{C}\right.$ ) and humidity (50-60\%) conditions and with free access to powdered rodent chow (diet AO4, Panlab, Spain) and water ( $\mathrm{pH}$ 5.5). In this study, the "Principles of Laboratory Animal Care" (NIH publication 83-25, revised 1985) were followed.

\subsection{Biochemical parameters - plasma analysis}

A portion of blood from rats in each group was collected into EDTA vacutainer tubes. Plasma was isolated after centrifuging blood in a previously refrigerated centrifuge at $1500 \mathrm{rpm}$ for $10 \mathrm{~min}$ and was sent to the clinical laboratory of the School of Pharmacy (University of Coimbra) for standard clinical tests to determine liver function (alanine aminotransferase and aspartate aminotransferase, indicating the degree of hepatolysis as well as conjugated, free and total plasma bilirubin) and chemistry profiles.

\subsection{Histological analysis}

After animal sacrifice, one testis and respective epididymis were dissected out and fixed in Bouin's fluid for $24 \mathrm{~h}$. After incubations in increasing levels of alcohol (70\%, 90\%, and 100\%) and benzol, tissues were processed in the normal paraffin procedure and sectioning ( $5 \mu \mathrm{m}$ thick). Then, the sections were de-paraffinized with xylol and incubated with decreasing levels of alcohol $(100 \%$, $75 \%$, and 50\%). All the slides were stained with hematoxilin and eo$\sin (\mathrm{H}$ and $\mathrm{E})$. The samples were covered with coverslips with Eukitt mounting medium. The epithelium of the seminiferous tubules of the testes and the content of the lumina of the caput and cauda epidydimis were microscopically examined.

For stages evaluation, the percentages of different cellular associations (14 in the rat) were evaluated in 100 tubules of each testis at $\times 1000$ magnification in a DM4000 Leyca Microscope. For histomorphometry analysis, cross sections of seminiferous tubules (100 diameters per animal) were measured (in micrometers $\mu \mathrm{m}$ ). All measurements were made per section using Leica application suite software.

For histopathological analysis, in all 100 seminiferous tubules, major (missing generations, sertoli cell only syndrome, pachytene arrest and degenerating epithelium) and minor (degenerating germ cells, multinucleated giant cells, germinative cells in lumen, residual bodies in the lumen, meiosis anomalies, and vacuolization) alterations were evaluated, and quantified. In the same way, lumen content of caput and cauda epididymis were evaluated. Major (absence of spermatozoa, germ cells and degenerating germ cells existence) and minor (observation of degenerating spermatid head, epithelial cells, cytoplasmatic droplet, and degenerated spermatid head) alterations were evaluated. For each parameter, 50 tubules were analyzed.

\subsection{Isolation of testis mitochondria}

Testis mitochondria from male Wistar rats (250-300 g) and STZ-treated rats were prepared as follows, according to a modified methodology of Gazzotti et al., 1979: the animals were sacrificed by cervical dislocation and the testes were immediately excised with adherent epididymis and vas deferens. Following testis and epididymis weighting, testis were decapsulated and minced finely several times in an ice-cold isolation medium containing $250 \mathrm{mM}$ sucrose, $0.2 \mathrm{mM}$ EGTA, $0.1 \mathrm{mM}$ EDTA, $5 \mathrm{mM}$ HEPES-KOH (pH 7.4) and $0.1 \%$ defatted bovine serum albumin (BSA). The minced blood-free tissue was then ressuspended in isolation medium and homogenized with a tightly fitted homogeniser (Teflon:glass pestle). The homogenate was then centrifuged at $2,500 \mathrm{~g}$ for 10 min (Sorvall RC-5C, Plus, SS 34 rotor, $4{ }^{\circ} \mathrm{C}$ ). The resulting supernatant fluid was centrifuged at $10,000 \mathrm{~g}$ for $10 \mathrm{~min}$. The pellet (mitochondrial fraction) was ressuspended using a paintbrush and repelleted twice at 10,000 $\mathrm{g}$ for $10 \mathrm{~min}$. EGTA, EDTA, and defatted BSA were omitted from the washing medium. Mitochondrial protein content was determined by the biuret method calibrated with BSA. 
The measurement of mitochondrial isolation yield (mitochondrial content) was performed using the citrate synthase assay, according to Coore et al. (1971).

\subsubsection{Mitochondrial oxygen consumption}

Oxygen consumption of isolated testis mitochondria was monitored polarographically with a Clark-type oxygen electrode (Estabrook, 1967) connected to a suitable recorder in a 2-ml thermostated water-jacketed closed chamber under magnetic stirring, at $27^{\circ} \mathrm{C}$. The standard respiratory medium consisted of $65 \mathrm{mM} \mathrm{KCl}, 125 \mathrm{mM}$ sucrose, $10 \mathrm{mM}$ Tris, $20 \mu \mathrm{M}$ EGTA, $2.5 \mathrm{mM}$ $\mathrm{KH}_{2} \mathrm{PO}_{4}, \mathrm{pH}$ 7.4. Mitochondria were suspended at a concentration of $0.8 \mathrm{mg} / \mathrm{ml}$ in the respiratory medium and were energized with both glutamate-malate and succinate as substrates. Additionally, when succinate was used, $3 \mu \mathrm{M}$ rotenone was added to the medium. ADP $(25 \mu \mathrm{M})$ was added to induce state III respiration. State IV respiration, was measured as the resting oxygen consumption after complete ADP phosphorylation. FCCP (carbonylcyanide-ptrifluoromethoxyphenylhydrazone- $0.5 \mu \mathrm{M}$ ) was added to induce uncoupled respiration. $\mathrm{RCR}$ and $\mathrm{ADP} / \mathrm{O}$ ratios were calculated according to Chance and Williams (1956). The respiratory control ratio (RCR) was determined as the ratio between mitochondrial respiration states 3 (consumption of oxygen in the presence of substrate and ADP) and 4 (consumption of oxygen after ADP has been consumed). The ADP/O ratio, an indicator of the efficiency of phosphorylation system, is expressed as the ratio between the amount of ADP added (nmol) and the oxygen consumed during the state 3 of respiration (natoms $\mathrm{O}$ ).

\subsubsection{Measurement of mitochondrial transmembrane potential}

Mitochondria were energized with $5 \mathrm{mM}$ succinate or $5 \mathrm{mM}$ glutamate-malate. The mitochondrial transmembrane electric potential $(\Delta \psi)$ was estimated with a tetraphenyl phosphonium $\left(\mathrm{TPP}^{+}\right)$electrode according to the equation of Kamo et al. (1979), without correction for the "passive" binding contribution of $\mathrm{TPP}^{+}$ to the mitochondrial membranes as the purpose of the experiment was to show relative changes in the potential rather than absolute values. A matrix volume of $1.1 \mu \mathrm{L} / \mathrm{mg}$ protein was assumed. Reactions were carried out, at $27^{\circ} \mathrm{C}$, in $1 \mathrm{ml}$ of the reaction media (65 mM KCl, $125 \mathrm{mM}$ sucrose, $10 \mathrm{mM}$ Tris, $20 \mu \mathrm{M}$ EGTA, $2.5 \mathrm{mM}$ $\mathrm{KH}_{2} \mathrm{PO}_{4}, \mathrm{pH}$ 7.4) supplemented with $3 \mu \mathrm{M}$ rotenone (when the substrate used was succinate), $2 \mu \mathrm{M} \mathrm{TPP}^{+}$, and $0.8 \mathrm{mg}$ mitochondria.

\subsubsection{Calcium accumulation by testicular mitochondria}

2.5.3.1. $\mathrm{TPP}^{+}$uptake. The mitochondrial tetraphenyl phosphonium $\left(\mathrm{TPP}^{+}\right)$uptake (indirect measurement of mitochondrial $\Delta \psi$ ) was performed using a $\mathrm{TPP}^{+}$selective electrode as described by Oliveira et al. (2004), using a $\mathrm{Ag} / \mathrm{AgCl}$ reference electrode (Kamo et al., 1979). Mitochondrial protein $(0.8 \mathrm{mg})$ was suspended in $1 \mathrm{ml}$ of reaction buffer ( $65 \mathrm{mM} \mathrm{KCl}, 125 \mathrm{mM}$ sucrose, $10 \mathrm{mM}$ Tris, $20 \mu \mathrm{M}$

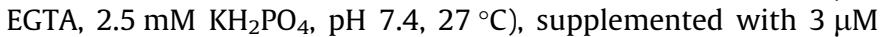
rotenone and $0.5 \mu \mathrm{M} \mathrm{TPP}{ }^{+}$. Sequential additions of $0.5 \mu \mathrm{M} \mathrm{TPP}{ }^{+}$ up to $3 \mu \mathrm{M}$ were made in order to calibrate the system. Succinate ( $5 \mathrm{mM}$ ) was added to the mitochondrial suspension in the absence and the presence of $50 \mu \mathrm{M}$ calcium. In each assay, the calibration was used to calculate the $\mathrm{TPP}^{+}$accumulated inside mitochondria in the presence and absence of calcium.

2.5.3.2. Calcium-induced depolarization - effects on $\triangle \psi$. A $\mathrm{TPP}^{+}$ selective electrode (Kamo et al., 1979) was used to assess some parameters normally associated with the MPTP opening namely mitochondrial $\Delta \psi$ loss and decrease in calcium loading capacity. The mitochondrial transmembrane potential was estimated as described in Section 2.5.2. Mitochondrial testis protein (1 mg) was resuspended in $1 \mathrm{ml}$ of reaction media (200 mM sucrose, $10 \mathrm{mM}$
TRIS-MOPS, $10 \mu \mathrm{M}$ EGTA, $2.5 \mathrm{mM} \mathrm{KH}_{2} \mathrm{PO}_{4}$ ) pH 7.4, supplemented with $3 \mu \mathrm{M}$ rotenone, $27^{\circ} \mathrm{C}$. Calcium $400 \mu \mathrm{M}$ was added in order to induce the MPTP. Mitochondrial energization was obtained with $5 \mathrm{mM}$ succinate. To inhibit the induction of MPTP, cyclosporin A $(0.5 \mu \mathrm{M})$ was added to the mitochondrial suspension before energization.

2.5.3.3. Mitochondrial swelling. Mitochondrial osmotic volume changes were followed by the decrease of absorbance at $540 \mathrm{~nm}$ with a Jasco V-560 spectrophotometer (Palmeira and Madeira, 1997). The assays were performed in $2 \mathrm{~mL}$ of the reaction media (200 mM sucrose, $10 \mathrm{mM}$ Tris-MOPS, $10 \mu \mathrm{M}$ EGTA, $2.5 \mathrm{mM}$ $\mathrm{KH}_{2} \mathrm{PO}_{4}$, supplemented with $3 \mu \mathrm{M}$ rotenone, and $5 \mathrm{mM}$ succinate and with $1 \mathrm{mg}$ protein. Calcium $(200 \mu \mathrm{M})$ was added to the preparation some minutes after the start of the experiment. To confirm the relationship between membrane permeability transition (MPT) induction and mitochondrial swelling, cyclosporin A $(0.25 \mu \mathrm{M})$ was added to the mitochondrial preparation before the addition of calcium.

2.5.3.4. Fluorimetric assay. For experiments concerning rate and amount of calcium accumulated by mitochondria, extramitochondrial free $\mathrm{Ca}^{2+}$ was measured with the hexapotassium salt of the fluorescent probe calcium green 5-N (A 12222, molecular probes), according to Rajdev and Reynolds (1993). Testis mitochondria ( $1 \mathrm{mg}$ ) were ressuspended in $2 \mathrm{ml}$ buffer containing $200 \mathrm{mM}$ sucrose, $10 \mathrm{mM}$ TRIS-MOPS, $10 \mu \mathrm{M}$ EGTA, $2.5 \mathrm{mM} \mathrm{KH}_{2} \mathrm{PO}_{4}$, pH 7.4, supplemented with $5 \mathrm{mM}$ succinate and $3 \mu \mathrm{M}$ rotenone. Free $\mathrm{Ca}^{2+}$ was monitored with $500 \mathrm{nM}$ calcium green 5-N. A pulse of $50 \mu \mathrm{M}$ calcium was added and to evaluate the induction of membrane transition pore we also add cyclosporin A to our assays. Fluorescence was continuously recorded in a water-jacketed cuvet holder at $25^{\circ} \mathrm{C}$ with a Perkin-Elmer LS-55B fluorescence spectrometer with excitation and emission wavelengths of 506 and $531 \mathrm{~nm}$, respectively. After proper calibration (minimum fluorescence signal, with an excess of EGTA), we determined the lowest fluorescence values recorded, that corresponds to the maximum calcium uptake by mitochondria.

\subsubsection{Mitochondrial enzymatic activities}

Mitochondrial ATPase activity was evaluated by following the amount of proton released upon ATP hydrolysis, through a potentiometric method as described previously by Madeira et al. (1974). The reaction was carried out at $27^{\circ} \mathrm{C}$ in $1 \mathrm{ml}$ reaction media (65 mM KCl, 125 mM sucrose, $20 \mu \mathrm{M}$ EGTA, $2.5 \mathrm{mM} \mathrm{KH}_{2} \mathrm{PO}_{4}$, pH 7.4).

$\mathrm{NADH}$ cytochrome $\mathrm{c}$ reductase and succinate cytochromse $\mathrm{c}$ reductase were assayed spectrophotometrically while cytochrome C oxidase (COX) activity was measured polarographically according to Moreira et al. (2004).

\subsubsection{Production of mitochondrial hydrogen peroxide measurements}

Hydrogen peroxide $\left(\mathrm{H}_{2} \mathrm{O}_{2}\right)$ production in isolated mitochondria was followed by measuring the conversion of Amplex red (Molecular probes, A 12222), in the presence of extramitochondrial horseradish peroxidase, to highly fluorescent resorufin, with an 1:1 stoichiometry (Zhou et al., 1997). Mitochondrial suspensions $(0.6 \mathrm{mg})$ were incubated in the presence of $50 \mu \mathrm{M}$ Amplex red and $2 \mathrm{U} / \mathrm{mL}$ horseradish peroxidase, and fluorescence was monitored over time using a temperature-controlled $\left(35^{\circ} \mathrm{C}\right)$ Perkin-Elmer LS-55B fluorescence spectrometer with excitation and emission wavelengths of 563 and $587 \mathrm{~nm}$, respectively, with gentle continuous stirring. Under these conditions, a linear increment in fluorescence indicates the rate of $\mathrm{H}_{2} \mathrm{O}_{2}$ released from mitochondria, which reacts with the peroxidase. Background fluorescence was measured in the absence of mitochondria. In a typical experiment, mitochondria were incubated at $0.6 \mathrm{mg}$ protein $/ \mathrm{ml}$ at $35^{\circ} \mathrm{C}$. 
$\mathrm{H}_{2} \mathrm{O}_{2}$ production was initiated in mitochondria using glutamate/ malate $(5 \mathrm{mM})$, or succinate $(5 \mathrm{mM})$ as substrates. Rotenone $(1.5 \mu \mathrm{M})$ and antimycin $\mathrm{A}(0.25 \mu \mathrm{g})$ were added to the incubation medium to inhibit the activities of complexs I and III, respectively. Pré-incubation with catalase (643 units $/ \mathrm{ml}$ ) decreased fluorescence as expected and was used to dissipate $\mathrm{H}_{2} \mathrm{O}_{2}$ in the incubation system. The rate of $\mathrm{H}_{2} \mathrm{O}_{2}$ production was linear with respect to $\mathrm{mg}$ of mitochondrial protein.

\subsubsection{Antioxidant capacity}

2.5.6.1. Measurement of glutathione and vitamin E content. Reduced (GSH) and oxidized (GSSG) glutathione were determined by fluorescence detection after reaction of the supernatant of the $\mathrm{H}_{3} \mathrm{PO}_{4} /$ EDTA- $\mathrm{NaH}_{2} \mathrm{PO}_{4}$ or $\mathrm{H}_{3} \mathrm{PO} / \mathrm{NaOH}$ deproteinized mitochondria solution, respectively, with o-phthalaldehyde (OPT), $\mathrm{pH}$ 8.0, according to Hissin and Hilf (1976). In brief, $0.5 \mathrm{mg}$ of each mitochondrial suspension was rapidly centrifuged at 50,000 rpm (Beckman, TL-100 Ultracentrifuge) for $20 \mathrm{~min}$ with $750 \mu \mathrm{l}$ phosphate buffer (100 mM NaH ${ }_{2} \mathrm{PO} 4,5 \mathrm{mM}$ EDTA, pH 8.0) and $250 \mu \mathrm{H}_{3} \mathrm{PO}_{4}$ $2.5 \%$. For GSH determination, $100 \mu \mathrm{l}$ of the supernatant was added to $1.8 \mathrm{ml}$ phosphate buffer and $100 \mu \mathrm{l}$ OPT. After mixing and incubation at room temperature for $15 \mathrm{~min}$, the solution was transferred to a quartz cuvette and the fluorescence was measured at $420 \mathrm{~nm}$. For GSSG determination, $250 \mu$ of the supernatant was added to $100 \mu \mathrm{l}$ of $\mathrm{N}$-ethylmaleymide and incubated at room temperature for $30 \mathrm{~min}$. After incubation, $140 \mu \mathrm{l}$ of the mixture was added to $1.76 \mathrm{ml} \mathrm{NaOH}(100 \mathrm{mM})$ buffer and $100 \mu \mathrm{l}$ OPT. After mixing and incubation at room temperature for $15 \mathrm{~min}$, the solution was transferred to a quartz cuvette and the fluorescence was measured at 420 and $350 \mathrm{~nm}$ emission and excitation wavelengths, respectively. GSH and GSSG contents were determined from comparisons with a linear reduced or oxidized glutathione standard curve, respectively.

Extraction of vitamin E ( $\alpha$-tocopherol) was performed by following a previously described method by Vatassery et al. (1983). Briefly, after sample preparation, vitamin E content was analyzed by reverse phase high performance liquid chromatography (HPLC). A Spherisorb Slow column $(4.6 \times 200 \mathrm{~mm})$ was eluted with $n$-hexane modified with $0.9 \%$ methanol, at a flow of $1.5 \mathrm{ml} / \mathrm{min}$. Detection was performed by a UV detector, at $287 \mathrm{~nm}$. The levels of mitochondrial vitamin E were calculated as nmoles/mg protein.

\subsubsection{Western Blot}

Frozen mitochondrial pellets were homogenized in lysis buffer (1 M urea, $10 \mathrm{mM}$ Tris, 2\% SDS, pH 7.5). Aliquots with equal protein content $(50 \mu \mathrm{g})$ were fractionated in $12 \%$ polyacrylamyde gels. Electrophoresis was carried out for one hour with $30 \mathrm{~mA}$ per gel and afterwards the separated proteins were transferred to polyvinylidene difluoride membranes, which were blocked for one hour in a $5 \%$ non-fat milk solution at $37^{\circ} \mathrm{C}$. The blocked membranes were incubated overnight at $4{ }^{\circ} \mathrm{C}$ with rabbit anti-Bax (1:500, Cell Signaling \# 2772) or rabbit polyclonal anti-PARP (1:200, Santa Cruz sc 7150), rabbit polyclonal anti-Flip s/1 (1:500, Santa Cruz sc 8347) and rabbit antibody against a subunit of the respiratory chain protein cytochrome oxidase IV (COX IV- 1:1000, Cell Signaling \# 4844). The immuno-reactive proteins were detected separately and were visualized with goat anti-rabbit IgG-AP (1:5000, Santa Cruz, SC 2007). Membranes were reacted with ECF detection system (GE Healthcare) and read with the Versa Doc imaging system (Bio-Rad). Densities from each band were obtained with Quantity One Software (Bio-Rad) (Oliveira and Wallace, 2006).

\subsection{Statistical analysis}

All statistical analyses were done using the SPSS (statistical package for the social sciences program), version 16.00 , software for windows (SPSS Inc., Chicago, IL, USA). All variables were checked for normal distribution. Results are presented as mean \pm S.E.M. of the number of experiences indicated and statistical significance between diabetic and control rat groups was accessed using the independent samples $t$-test. Multiple comparisons were performed using one way Anova, and $p \leqslant 0.05$ was considered significant. Bivariate correlation $(r)$ in different groups was evaluated by calculating the Pearson correlation coefficient with a two-tailed significance $(p)$.

For histological analysis, except in diameter variable, statistical significance between diabetic and control rat groups was accessed using the Mann-Whitney U-test and $p \leqslant 0.05$ was considered significant. Bivariate correlation $(r)$ in different groups was evaluated by calculating the Spearman correlation coefficient with a twotailed significance $(p)$.

\section{Results}

\subsection{Animal characterization}

\subsubsection{Glycemia/body and reproductive organs weight/biochemical sparameters}

As expected, blood glucose (non fasting) levels, were significantly higher in STZ diabetic rats when compared to respective controls $(p \leqslant 0.01)$. STZ-treated rats presented severe hyperglycemias $(>448 \mathrm{mg} / \mathrm{dL}$ ) in contrast with normoglycemic controls $(<103 \mathrm{mg} / \mathrm{dl}$ ). Diabetic animals experienced a significant loss in body and reproductive organs weight when compared to controls $(p \leqslant 0.01)$ (Table 1$)$.

Relatively to plasma analyses, an elevation of the activity of the hepatic marker enzymes, alanine aminotransferase $(p \leqslant 0.01)$, aspartate aminotransferase $(p \leqslant 0.05)$ and alkalyne phosphatase $(p \leqslant 0.001)$ were observed in blood plasma of STZ diabetic animals. These changes might indicate a steatosis state in the liver, however no alterations in liver macroappearance were observed. No differences were observed in activity of Gamma glutamyl transpeptidase or total and conjugated bilirubin between experimental groups (Table 1).

\subsection{Histological analysis}

No differences were found in stage frequencies between animal groups (data not shown). Nonetheless, rats treated with STZ had lower tubular diameter when compared to controls $(p \leqslant 0.05)$. Additionally, STZ-treated rats present a higher percentage of tubules with alterations such as vacuolization, missing generations, appearance of multinucleated cells and presence of degenerated cells. We have also observed the presence of degenerated epithelium in the STZ-treated group (Fig. 1). Caput and cauda epididymis from STZ-treated rats showed a higher percentage of tubules with immature round cells, degenerated sperm heads and residual bodies in the lumen (Fig. 1). As expected, the presence of cytoplasmatic droplets in sperm decreases in frequency from caput to cauda, were they are absent. However, rats treated with STZ for 3 months constitute an exception since cytoplasmatic droplets in sperm from cauda epididymis were observed. Additionally, histological examination of the STZ-treated epididymis showed a general decrease in the number of sperm visible within the caput epididymis, with some animals showing complete absence of sperm (data not shown).

\subsection{Studies of mitochondrial respiration and mitochondrial transmembrane potential}

The mitochondrial proton gradient originates an electrochemical potential $(\Delta p)$ resulting in a $\mathrm{pH}(\Delta \mathrm{pH})$ and in a voltage gradient 
Table 1

Characterization of Wistar control and diabetic rats.

\begin{tabular}{|c|c|c|c|}
\hline & & Wt. control & STZ \\
\hline \multirow[t]{4}{*}{ Weights } & Body weight (g) & $396.39 \pm 19.2$ & $314.02 \pm 10.24^{* *}$ \\
\hline & Testis weight (g) & $1.95 \pm 0.07$ & $1.63 \pm 0.07^{* *}$ \\
\hline & Epidydimus weight (g) & $0.73 \pm 0.03$ & $0.52 \pm 0.036^{* * *}$ \\
\hline & Testis/body weight (g) & $0.51 \pm 0.00$ & $0.52 \pm 0.00$ \\
\hline \multirow[t]{8}{*}{ Blood biochemical parameters } & Glycemia (mg/dl) & $90.03 \pm 3.1$ & $532.33 \pm 15.9^{* * *}$ \\
\hline & Total bilirubin (mg/dl) & $1.32 \pm 0.11$ & $1.47 \pm 0.22$ \\
\hline & Conjugated bilirubin (mg/dl) & $0.47 \pm 0.05$ & $0.55 \pm 0.08$ \\
\hline & Cholesterol (mg/dl) & $47 \pm 2.39$ & $55.13 \pm 3.19$ \\
\hline & Alanine aminotransferase (U/I) & $50.40 \pm 3.76$ & $109.33 \pm 15.12^{* *}$ \\
\hline & Aspartate aminotransferase (U/L) & $199.22 \pm 24.26$ & $374.0 \pm 55.6^{*}$ \\
\hline & Alkaline phosphatase (U/L) & $44.6 \pm 3.77$ & $124.43 \pm 12.95^{* * *}$ \\
\hline & Gamma glutamyl transpeptidase (U/L) & $5.14 \pm 0.14$ & $11.28 \pm 2.32$ \\
\hline
\end{tabular}

Data show means \pm SEM. ${ }^{*} p<0.05,{ }^{* *} p<0.01$ and ${ }^{* * *} p<0.001$ when compared to Wistar control animals. All values were determined as described in Section 2 .
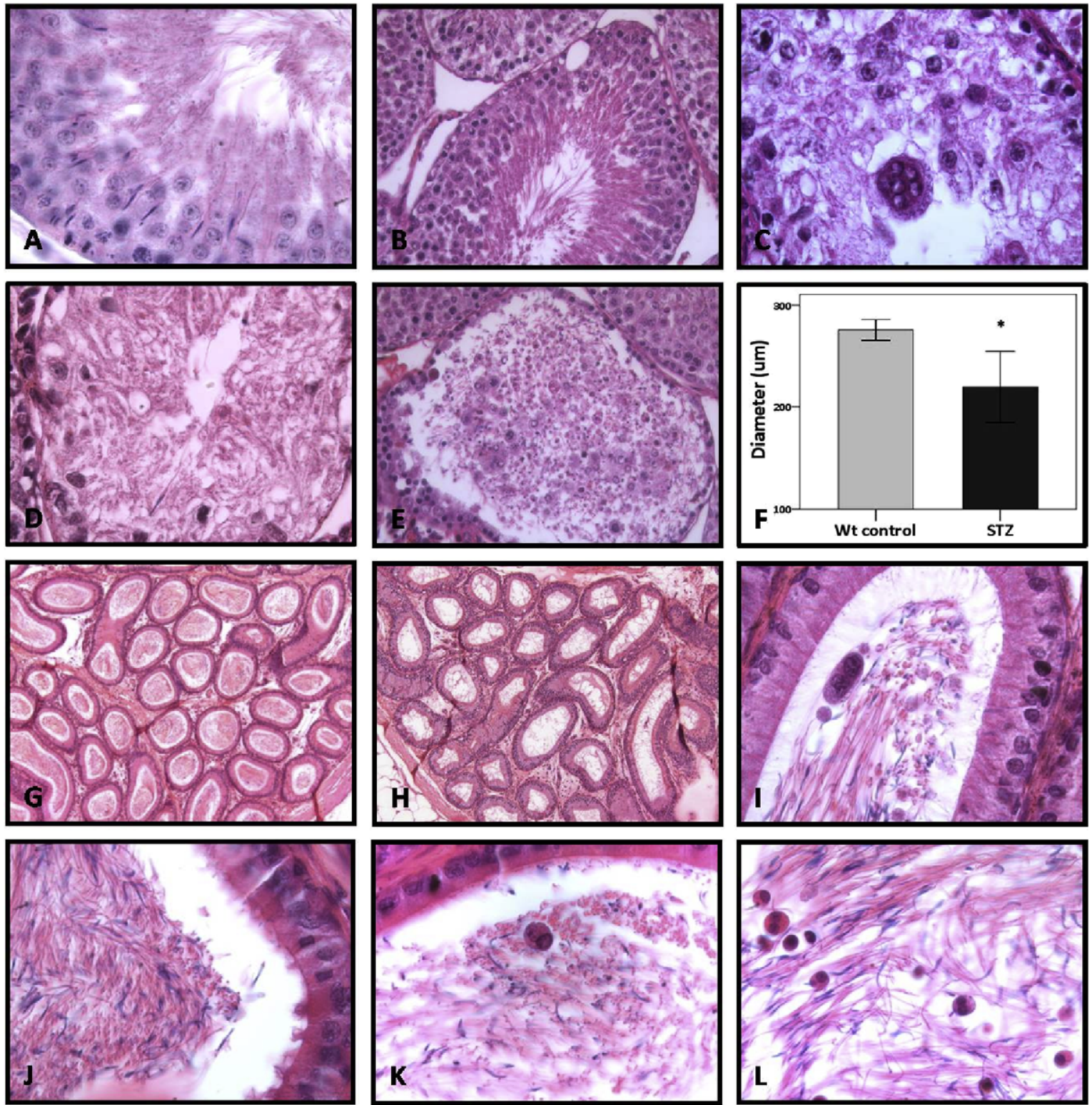

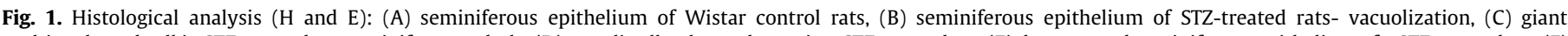

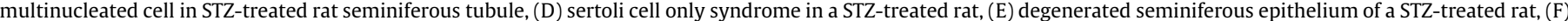

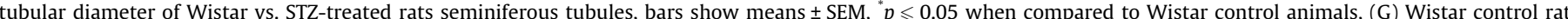

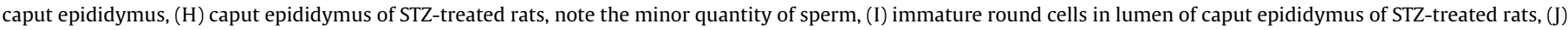

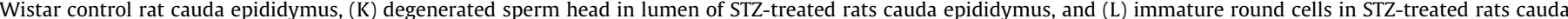

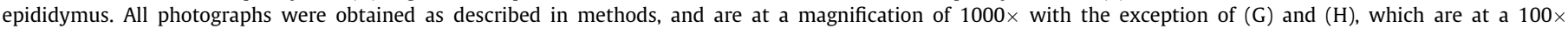
magnification. 
Table 2

Respiratory function and transmembrane electrical potential parameters in Wistar control rats and diabetic rats.

\begin{tabular}{|c|c|c|c|}
\hline & & Wt. control & STZ-treated \\
\hline \multirow[t]{9}{*}{ Complex I } & State 3 (natmsO/min/mg prot) & $22.61 \pm 1.26$ & $20.00 \pm 1.35$ \\
\hline & State 4 (natmsO $/ \mathrm{min} / \mathrm{mg}$ prot) & $14.01 \pm 0.82$ & $10.50 \pm 0.89$ \\
\hline & $\mathrm{FCCP}$ (natmsO/min/mg prot) & $16.01 \pm 1.4$ & $22.03 \pm 2.2^{*}$ \\
\hline & $\mathrm{RCR}$ & $1.7 \pm 0.107$ & $1.93 \pm 0.12$ \\
\hline & $\mathrm{ADP} / \mathrm{O}$ & $3.32 \pm 0.18$ & $3.78 \pm 0.28$ \\
\hline & $\Delta \psi \max (-\mathrm{mv})$ & $201.64 \pm 2.28$ & $204.69 \pm 1.41$ \\
\hline & Repolarization $\Delta \psi(-\mathrm{mV})$ & $191.02 \pm 2.93$ & $196.53 \pm 1.73$ \\
\hline & ADP-induced depolarization $(-\mathrm{mV})$ & $17.94 \pm 0.46$ & $16.64 \pm 0.64$ \\
\hline & Lag phase(s) & $37.08 \pm 3.03$ & $32.77 \pm 2.41$ \\
\hline \multirow[t]{9}{*}{ Complex II } & State 3 (natmsO/min/mg prot) & $31.30 \pm 1.52$ & $27.69 \pm 1.5$ \\
\hline & State 4 (natmsO/min/mg prot) & $25.52 \pm 1.62$ & $21.64 \pm 1.49$ \\
\hline & $\mathrm{FCCP}$ (natmsO/min/mg prot) & $40.70 \pm 2.98$ & $44.83 \pm 3.51$ \\
\hline & $\mathrm{ADP} / \mathrm{O}$ & $1.78 \pm 0.24$ & $1.82 \pm 0.12$ \\
\hline & $\mathrm{RCR}$ & $1.27 \pm 0.05$ & $1.29 \pm 0.04$ \\
\hline & $\Delta \psi \max (\mathrm{mV})$ & $198.67 \pm 2,6$ & $200.33 \pm 2.66$ \\
\hline & Repolarization $\Delta \psi(\mathrm{mV})$ & $193.9 \pm 3.03$ & $196.65 \pm 2.3$ \\
\hline & ADP-induced depolarization (mV) & $20.00 \pm 0.75$ & $19.44 \pm 1.01$ \\
\hline & Lag phase (s) & $58.1 \pm 7.4$ & $48.12 \pm 2$ \\
\hline
\end{tabular}

Data show means \pm SEM. ${ }^{*} p \leqslant 0.05$ when compared to Wistar control animals. All values were determined as described in Section 2 .

$(\Delta \psi m)$ across the mitochondrial inner membrane (Newmeyer and Ferguson-Miller, 2003). Transmembrane electrical potential $(\Delta \psi)$ is the main component of the electrochemical gradient $(\mu \mathrm{H}+)$, accounting for more than $90 \%$ of the total protonmotive force (Moreira et al., 2005). Therefore, the determination of alterations associated with $\Delta \psi$ is of major importance in studies of mitochondrial oxidative phosphorylation.

Since there were no significant differences in mitochondrial content per milligram of protein in control and diabetic rats as monitored by the citrate synthase activity assay (data not shown), we evaluated oxygen consumption and membrane potential fluctuations in testis mitochondria from the two experimental groups using complex-specific substrates: glutamate-malate for complex I and succinate for complex II.

No differences were observed between the two animal groups in both maximum $\Delta \psi$ (after substrate addition) and in state 3 respiration, the last evaluated in the presence of both substrates and induced by the addition of $25 \mathrm{nmol}$ ADP (Table 2). The same pattern was observed in the depolarization following ADP addition and in phosphorylation lag phase where no differences were found between control and diabetic testicular mitochondria (Table 2 ). Additionally, the absence of differences was also evident in ADP/O between control and STZ diabetic animal, for both substrates, suggesting that phosphorylative efficiency is not compromised in diabetic testis. After ADP depletion, when measuring state 4 respiration (resting oxygen consumption) in the presence of glutamate-malate, we found that the value obtained decreased in STZ diabetic animals $(p \leqslant 0.05)$ (Table 2$)$. No differences were observed when the $\Delta \psi$ recovered after ADP phosphorylation between two animal groups (Table 2). However, uncoupled respiratory rate (stimulated by FCCP) was higher in diabetic animals $(p \leqslant 0.05)$.

Respiratory control ratio (RCR), a measure of mitochondrial coupling between respiration and phosphorylation was also determined as shown in Table 2. Testicular mitochondria present lower RCR values when compared to other tissues from the same animal models (Moreira et al., 2005, 2006; Teodoro et al., 2006). However, no differences were found between the two experimental groups, regardless of the substrate used, suggesting that mitochondrial coupling is not affected in the testis of diabetic males.

Additionally, significant Pearson correlations $(p \leqslant 0.05)$ between electric potential parameters ( $\Delta \psi$ max, Repolarization $\Delta \psi$, ADP - induced depolarization) and state 3 oxygen consumption were observed in control animals, showing the functional relation between respiratory and electric potential components and con- firming that mitochondria is functional. Interestingly, these correlations disappear in STZ-induced diabetic animals.

\subsection{Calcium accumulation by testis mitochondria}

Mitochondria possess a finite capacity for accumulating calcium before undergoing the calcium-dependent mitochondria permeability transition (MPT). Calcium accumulation capacity of testis mitochondria from diabetic and control rats was determined using several methods, as described below. In these assays, succinate was the substrate used, as this allows for a fully reduced pool of pyridine nucleotides.

3.4.1. $\mathrm{TPP}^{+}$uptake, calcium induced $\triangle \psi m$ depolarization, swelling and direct evaluation of calcium loading capacity using calcium green 5-N

Mitochondrial transmembrane potential $(\Delta \psi \mathrm{m})$ depolarization (decrease of $\Delta \psi m$ ) is a typical phenomenon that follows the induction of MPTP (mitochondria permeability transition pore). $\mathrm{A} \mathrm{Ca}^{2+}$ pulse led to a rapid depolarization followed by a small repolarization (recover of $\Delta \psi m$ ). The depolarization was due to the entry of $\mathrm{Ca}^{2+}$ into the electronegative mitochondrial matrix, followed by the efflux of $\mathrm{H}^{+}$in an attempt to restore $\Delta \psi m$. However, excess $\mathrm{Ca}^{2+}$ can led to total depolarization of mitochondria. In order to follow $\mathrm{Ca}^{2+}$-induced depolarization, $\Delta \psi m$ was determined before and after $\mathrm{Ca}^{2+}$ addition and found to be depressed in STZ diabetic animals $(p \leqslant 0.05)$ in the last condition. Alternatively, the maximum amount of $\mathrm{TPP}^{+}$accumulated in the presence and absence of calcium was also determined, as described by Oliveira et al. (2004). Using this assay we demonstrated that testis mitochondria from STZ-treated rats are less capable of accumulating calcium when compared with the control group (Fig. 2).

Induction of the MPTP can be also monitored by following the decrease in absorbance associated with mitochondrial swelling (data not shown) or determination of extramitochondrial calcium movements, using the fluorescent calcium-sensitive probe calcium green 5-N (Fig. 2). However, no differences were found between control and diabetic animals in calcium loading capacity using these two methods.

\subsection{Mitochondrial enzymatic activities}

\subsubsection{Determination of NADH cytochrome c reductase, succinate} cytochrome c reductase, COX and ATPase activity

Studies of enzymatic activities of respiratory complexes were performed in order to localize which and if respiratory complexes are af- 


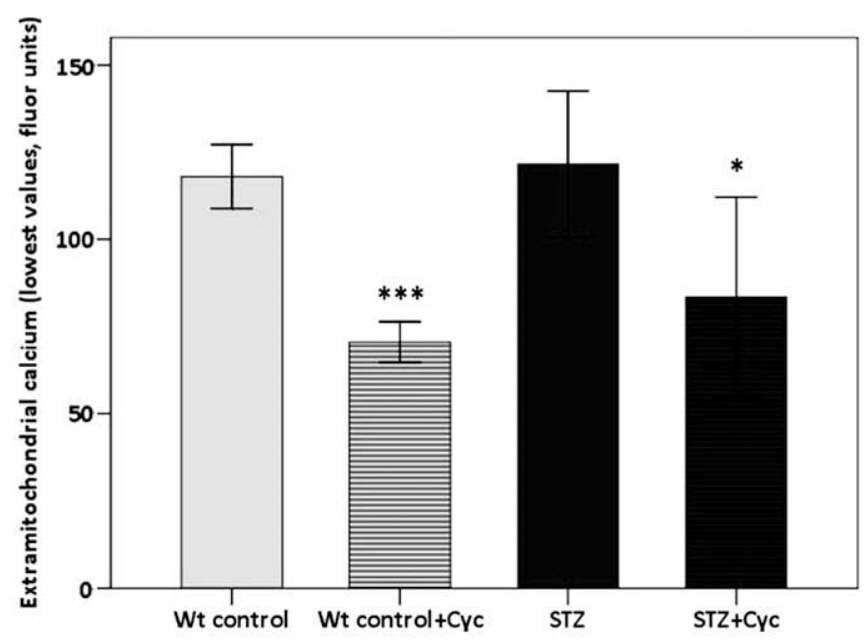

\begin{tabular}{|c|c|c|c|}
\hline & & Wt control & STZ \\
\hline \multirow{3}{*}{$\begin{array}{c}\mathrm{Ca}^{2+}-\text { induced depolarization } \\
(-\mathrm{mV})\end{array}$} & $\Delta \psi \max$ & $200.64 \pm 1.80$ & $198.25 \pm 1.00$ \\
\hline & $\Delta \psi \max p o s \mathrm{ca}^{2+}$ & $188.32 \pm 1.88$ & $180.17 \pm 2.18^{*}$ \\
\hline & $\Delta \psi \max p o s \mathrm{ca}^{2+} / \Delta \psi \max$ & $0.95 \pm 0.00$ & $0.92 \pm 0.01 *$ \\
\hline \multirow[t]{2}{*}{ TPP+ uptake } & $(-)_{c a^{2+}}$ & $1.62 \pm 0.07$ & $1.87 \pm 0.14$ \\
\hline & $(+) \mathrm{ca}^{2+}$ & $1.30 \pm 0.07$ & $1.62 \pm 0.12 *$ \\
\hline (nmolesTPP+/min/mg prot) & $(-) \mathrm{ca}^{2+} /(+) \mathrm{ca}^{2+}$ & $0.84 \pm 0.05$ & $0.82 \pm 0.49$ \\
\hline
\end{tabular}

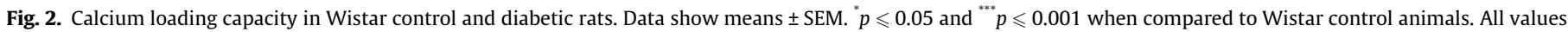
were determined as described in Section 2.

Table 3

Mitochondrial enzymatic activities in Wistar control and diabetic rats.

\begin{tabular}{llr}
\hline & Weight control & \multicolumn{1}{c}{ STZ } \\
\hline NADH-Cyt C reductase (nmoles/min/mg prot) & $97.39 \pm 6.07$ & $98.99 \pm 5.52$ \\
Succinate-Cyt C reductase (nmoles/min/mg prot) & $73.06 \pm 4.39$ & $72.09 \pm 3.26$ \\
Cytochrome C oxidase (natmsO/min/mg prot) & $178.2 \pm 13.88$ & $181.06 \pm 9.74$ \\
ATPase (nmol H $\left.\mathrm{m}^{+} / \mathrm{min} / \mathrm{mgprot}\right)$ & $25.76 \pm 4.3$ & $18.92 \pm 5.17$
\end{tabular}

Data show means \pm SEM. All values were determined as described in Section 2 .

fected by diabetes. NADH cytochrome c reductase (complexs I-III), succinate cytochrome $\mathrm{c}$ reductase (complexes II and III), COX (cytochrome $C$ oxidase - complex IV) and ATPase activities were not affected in STZ diabetic rats, when compared to controls (Table 3).

\subsection{Oxidative stress and antioxidant capacity - related measurements}

The production of $\mathrm{H}_{2} \mathrm{O}_{2}$ by mitochondria gives an indication on the propensity of mitochondria to originate or exacerbate oxidative stress. The fluorescent probe Amplex red was used to access $\mathrm{H}_{2} \mathrm{O}_{2}$ formation. We observed that STZ diabetic rats presented a similar production of $\mathrm{H}_{2} \mathrm{O}_{2}$ when compared to control animals (Fig. 3).

Endogenous antioxidants, such as reduced glutathione (GSH), and also external antioxidants like vitamin $\mathrm{E}$ belong to the first line of defense, acting by scavenging potentially damaging free radical moieties. In our study no significant diabetes-induced changes promoted were observed in terms of GSH or vitamin E concentrations (Fig. 3).

\subsection{Western Blot analysis of BAX, PARP, FLIP, and COX}

The balance between germ cell proliferation, differentiation and apoptosis is critical for the control of spermatogenesis. Changing the fine regulation of any of these processes may lead to the onset of testicular diseases (Giampietri et al., 2005). One well-characterized caspase-dependent marker of apoptosis is the cleavage and inactivation of poly-ADPribose polymerase (PARP), an enzyme involved in DNA repair. Also, Bax expression is stimulated upon the triggering of apoptosis (Said et al., 2004). On the other hand, FLIP belongs to a family of crucial relevance in apoptosis control, inhibiting apoptosis (Giampietri et al., 2005). However, the mitochondria of STZ diabetic animals did not present any change in the expression of these apoptotic markers, using COX as an internal control (data not shown).

\section{Discussion}

Increasing evidence suggests that both types of diabetes have an adverse effect on male reproductive function (Jiang, 1996; Sexton and Jarow, 1997; Rehman et al., 2001; Musicki and Burnett, 2007). Given that increased oxidative stress is a widely accepted participant in the development and progression of diabetes and its complications. (Ahmed, 2005; Ceriello, 2003; Maritim et al., 2003), and that mitochondria are a significant source of ROS, the impairment of mitochondrial function is intrinsically related with diabetes (Rolo and Palmeira, 2006; Yu et al., 2006; Ahmed, 2005; Ceriello, 2003; Wiernsperger, 2003; Gerbitz et al., 1995). In addition mitochondria are also involved in apoptosis (Crompton, 1999; Doran and Halestrap, 2000).

Importantly, the proper functioning of energy metabolism and catabolism testicular pathways is critical for testicular physiology (Erkkila et al., 2006) and mitochondria might have a role in these processes since morphology and energy metabolism of testicular mitochondria change markedly during spermatogenesis (Meinhardt et al., 1999). Additionally, ROS and mitochondrial dysfunc- 

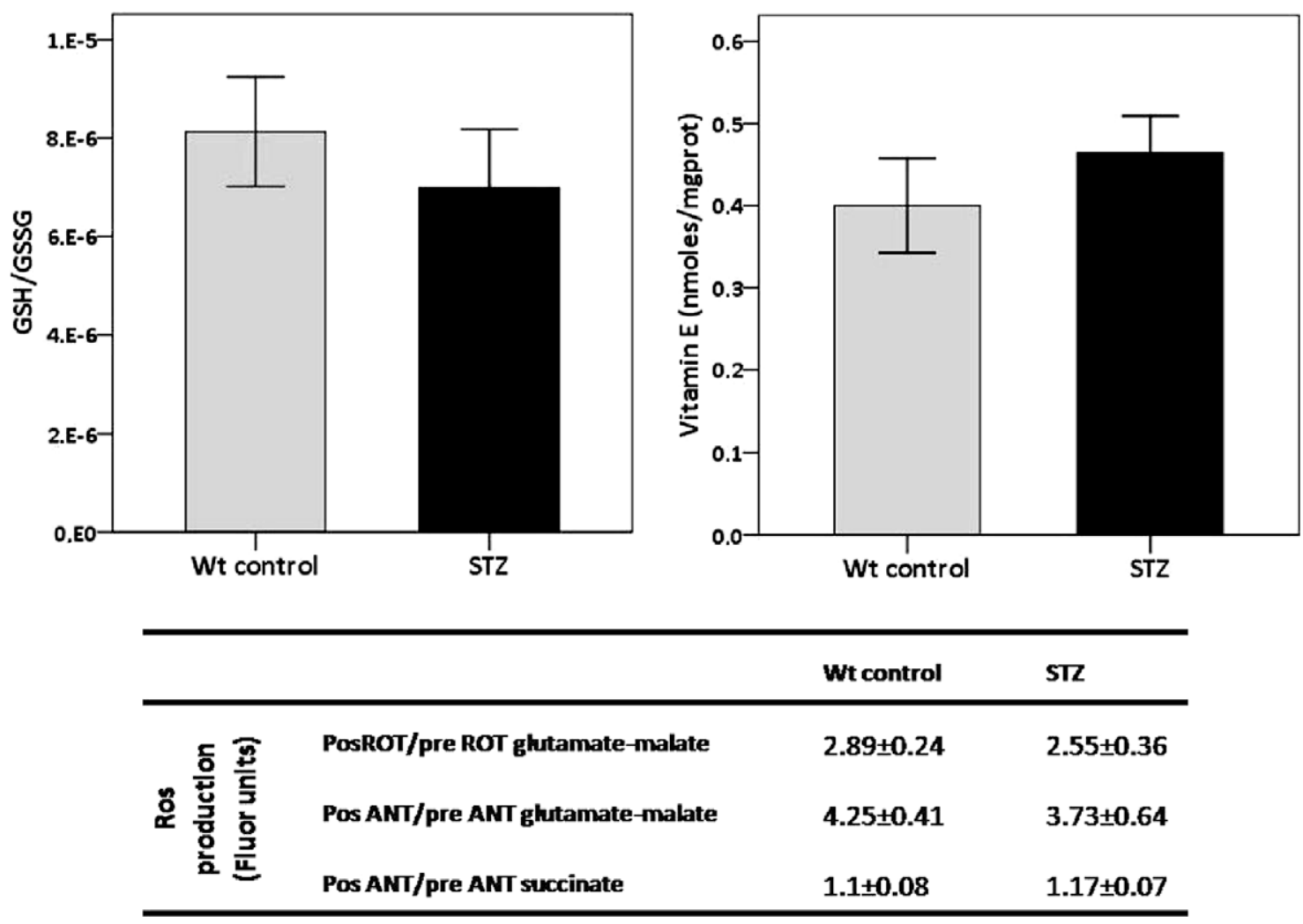

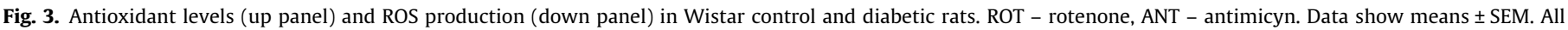
values were determined as described in Section 2.

tion are also involved in impairment of reproductive function (Agarwal et al., 2003; Amaral et al., 2008).

In previous work, we found a decrease in sperm concentration and motility in STZ-induced diabetic animals, as well as a decrease in ATP content in testicular cells (Amaral et al., 2006). In the present study, we have tried to clarify the effects of untreated type 1 diabetes on mitochondrial function, spermatogenesis and epididymal maturation in STZ-induced diabetic rats. Besides reduced reproductive organs and body weight, histological studies revealed a considerable reduction of seminiferous tubules diameter in STZtreated rats, as well as many alterations which impair spermatogenesis and sperm epidydimal maturation, contributing to declined fertility. These results are in accordance with the decreased sperm concentration and motility observed in diabetic type 1 rats, and points to defects in the seminiferous epithelium (Amaral et al., 2006; Sacarano et al., 2006; Soudamani et al., 2005; Hassan et al., 1993).

Considering that STZ-treated diabetic rats have lower testicular ATP levels (Amaral et al., 2006), we hypothesized that these impairments could be mediated by testicular mitochondria.

Interestingly, respiratory function was similar in STZ-treated and control rats. However, in diabetic animals there were slight changes in terms of a higher uncoupled respiratory rate, suggestive of increased number of respiratory complexes reserves, and lower resting oxygen consumption (state 4 ), suggesting a decrease in membrane proton leak. Given that most other respiratory parameters, membrane potential evaluations and mitochondrial enzymatic activities were unaffected in STZ diabetic animals, these results suggest that these animals probably acquired some metabolic adaptations in order to maintain mitochondrial function. Interestingly we observed a lack of correlations between respiratory and electric membrane parameters in diabetic animals (unlike what was found in controls), which is clearly not accompanied by a decreased mitochondrial function.
Previous studies in other organs reported a decline in the respiratory function in liver mitochondria of STZ-induced diabetic rats (Ferreira et al., 2003a) while others found that, similarly to what we describe here for the testis, STZ-induced diabetes did not substantially affect brain mitochondrial function (Moreira et al., 2004). A study in testicular mitochondria also shown that diabetic rats have decreased susceptibility to oxidative stress and a higher antioxidant capacity, however in this study, oxidative stress was induced with ADP $/ \mathrm{Fe}^{2+}$ (Palmeira et al., 2001). These results confirm the importance of studying mitochondrial bioenergetical parameters in different target tissues and under physiological conditions, and also suggest that both the blood-brain and testisblood barriers may protect mitochondria in these tissues from diabetes-induced damage in STZ-treated rats.

Another important role for mitochondria is calcium buffering, and in the presence of high external $\mathrm{Ca}^{2+}$ concentrations, isolated mitochondria can easily undergo the mitochondrial permeability transition (MPT) (Walter et al., 2000; Crompton, 1999). In fact, previous studies have focused in abnormalities in MPT during type 1 diabetes (Kristal et al., 1996; Oliveira et al., 2001) and work in brain and heart described a decrease in calcium loading capacity in mitochondria from STZ rats (Moreira et al., 2005; Oliveira et al., 2003). On the other hand, in the liver, a decrease susceptibility of mitochondria to the induction of the MPTP in diabetic STZ animals was observed (Ferreira et al., 2003b). Even though we could observe a higher calcium-induced decrease in mitochondrial $\Delta \psi$ in testicular mitochondria from STZ diabetic animals by using the $\mathrm{TPP}^{+}$electrode, no differences were observed when using the fluorescent calcium probe calcium green $5-\mathrm{N}$, suggesting augmented calcium cycling in diabetic testicular mitochondria or, alternatively, that calcium can damage more diabetic mitochondria, which then become less able to generate potential.

Contrasting with studies in brain mitochondria, where a higher production of $\mathrm{H}_{2} \mathrm{O}_{2}$ has been reported in STZ-treated rats (Moreira 
et al., 2005), in diabetic testicular mitochondria we did not observe any significant differences, also confirmed with unaltered levels of glutathione and vitamin $\mathrm{E}$ in type 1 diabetic animals. Additionally, the absence of differences in the protein levels of Bax, PARP and FLIP, is a sign that, at least at the mitochondrial level, apoptosis is also not affected in the testis of STZ diabetic rats.

Taken together, our results show that under the negative influence of a condition that mimics untreated type 1 diabetes, the rat testis answers rather monotonously by reducing spermatogenesis. Also, in this model the adverse effects of diabetes in reproduction are not directly related to mitochondrial dysfunction in the phase of disease we have studied and in terms of the parameters monitored, meaning that our previously results of decreased ATP contents in the testis of these animals (Amaral et al., 2006) are mitochondria-independent and could instead be related to substrate availability. Whether these findings are extendable to other diabetic animal models for either type of diabetes remains to be established.

\section{Acknowledgements}

S. Amaral would like to thanks M. Sancha Santos and A. Moreno for continuous technical assistance and useful discussions, Raquel Seiça for technical assistance in terms of STZ administration, Helena Oliveira for helping with histology procedures, J. Saints for language correction, C. Gomes and C. Ramos for statistical review, Raquel Santiago, Joana Gaspar from the "STZ group" and also Cláudio Batista and Ângela Amaral for continuous encouragement and support. S. Amaral is a recipient of a fellowship from FCT (SFRH/ $\mathrm{BD} / 18734 / 2004)$.

\section{References}

Agarwal, A., Saleh, R.A., Bedaiwy, M.A., 2003. Role of reactive oxygen species in the pathophysiology of human reproduction. Fertil. Steril. 79, 829-843.

Agbaje, I.M., Rogers, D.A., McVicar, C.M., McClure, N., Atkinson, A.B., Mallidis, C., Lewis, S.E., 2007. Insulin dependent diabetes mellitus: implications for male reproductive function. Hum. Reprod. 22, 1871-1877.

Ahmed, R.G., 2005. The physiological and biochemical effects of diabetes on the balance between oxidative stress and antioxidant defense system. Med. J. Islamic World Acad. Sci. 15, 31-42.

Amaral, S., Moreno, A.J., Santos, M.S., Seiça, R., Ramalhos-Santos, J., 2006. Effects of hyperglycemia on sperm and testicular cells of goto-kakizaki and streptozotocin-treated rat models for diabetes. Theriogenology 66, 2056-2067.

Amaral, S., Oliveira, P.J., Ramalho-Santos, J., 2008. Diabetes and impairment of reproductive function: possible role of mitochondria and reactive oxygen species. Curr. Diabetes Rev. 4, 46-54.

Baccetti, B., La Marca, A., Piomboni, P., Capitani, S., Bruni, E., Petraglia, F., De Leo, V. 2002. Insulin-dependent diabetes in me mis associated with hypothalamopituitary derangement and with impairement in semem quality. Hum. Reprod. $17,2673-2677$.

Berdanier, C.D., 2001. Diabetes and nutrition: the mitochondrial part. J. Nutr. 131 344-353.

Brownlee, M., 2001. Biochemistry and molecular cell biology of diabetic complications. Nature 414, 813-820.

Ceriello, A., 2003. New insights on oxidative stress and diabetic complications may lead to a "causal" antioxidant therapy. Diabetes Care 26, 1589-1596.

Chance, B., Williams, G.R., 1956. The respiratory chain and oxidative phosphorylation. Adv. Enzymol. 17, 65-134.

Coore, H.G., Denton, R.M., Martin, B.R., Rande, P.J., 1971. Regulation of adipose tissue pyruvate dehydrogenase by insulin and other hormones. Biochem. J. 125, 115127.

Crompton, M., 1999. The mitochondrial permeability transition pore and its role in cell death. Biochem. J. 341, 233-249.

Doran, E., Halestrap, A.P., 2000. Cytochrome c release from isolated rat liver mitochondria can occur independently of outer-membrane rupture: possible role of contact sites. Biochem. J. 348, 343-350.

Emilien, G., Maloteaux, J.M., Ponchon, M., 1999. Pharmacological management of diabetes: recent progress and future perspective of daily drug treatment Pharmacol. Ther. 81, 37-51.

Engelgau, M.M., Geiss, L.S., 2000. The burden of diabetes mellitus. In: Leahy, J.L., Clark, N.G., Cefalu, W.T. (Eds.), Medical Management of Diabetes Mellitus. Mark Dekker, New York, pp. 1-17.

Erkkila, K., Kyttanen, S., Wikstrom, M., Taari, K., Hikim, A.P., Swerdloff, R.S., Dunkel, L., 2006. Regulation of human male germ cell death by modulators of ATP production. Am. J. Physiol. Endocrinol. Metab. 290, 1145-1154.
Estabrook, R.E., 1967. Mitochondrial respiratory control and the polarographic measurement of ADP/O ratios. Methods Enzymol. 10, 41-47.

EURODIAB, 2000. Variation and trends in incidence of childhood diabetes in Europe. EURODIAB ACE Study Group. Lancet. 355, 873-876.

Ferreira, F.M., Palmeira, C.M., Seiça, R., Moreno, A.J., Santos, M.S., 2003a. Diabetes and mitochondrial bioenergetics: alterations with age. J. Biochem. Mol. Toxicol. 17, 214-222.

Ferreira, F.M., Seiça, R., Oliveira, P.J., Coxito, P.M., Moreno, A.J., Palmeira, C.M., Santos, M.S., 2003b. Diabetes induces metabolic adaptations in rat liver mitochondria: role of coenzyme Q and cardiolipin contents. Biochim. Biophys. Acta $1639,113-120$.

Gazzotti, P., Malmstron, K., Crompton, M., 1979. Preparation and assay of animal mitochondria and submitochondrial vesicles. In: Carafoli, E., Sememza, G. (Eds.), Membrane Biochemistry: A Laboratory Manual on Transport and Bioenergetics. Springer-Verlag, New York, pp. 62-69.

Gerbitz, K.D., van den Ouweland, J.M., Maassen, J.A., Jaksch, M., 1995. Mitochondrial diabetes mellitus: a review. Biochim. Biophys. Acta 1271, 253-260.

Giampietri, C., Petrungaro, S., Coluccia, P., D’Alessio, A., Starace, D., Riccioli, A., Padula, F., Palombi, F., Ziparo, E., Filippini, A., De Cesaris, P., 2005. Germ cell apoptosis control during spermatogenesis. Contraception 72, 298-302.

Hassan, A.A., Hassouana, M.M., Taketo, T., Gagnon, C., Elhiali, M.M., 1993. The effect of diabetes on sexual behaviour and reproductive tract function in male rats. J. Urol. 149, 148-154.

Hissin, P.J., Hilf, R., 1976. A fluorometric method for determination of oxidized and reduced glutathione in tissues. Anal. Biochem. 74, 214-226.

Jiang, G.Y., 1996. Practical Diabetes, first ed. Beijing People's Health Publishing House. p. 295

Kamo, N., Muratsugu, M., Hongoh, R., Kobatake, Y., 1979. Membrane potential of mitochondria measured with an electrode sensitive to tetraphenyl phosphonium and relationship between proton electrochemical potential and phosphorylation potential in steady state. J. Membr. Biol. 49, 105-121.

Kristal, B.S., Matsuda, M., Yu, B.P., 1996. Abnormalities in the mitochondrial permeability transition in diabetic rats. Biochem. Biophys. Res. Commun. 222, 519-523.

Madeira, V.M., Antunes-Madeira, M.C., Carvalho, A.P., 1974. Activation energies of the ATPase activity of sarcoplasmic reticulum. Biochem. Byophys. Res. Commum. 58, 597-904.

Malaisse, W.J., 1983. Insulin release: the fuel concept. Diabetes Metab. 9, 313-320.

Maritim, A.C., Sanders, R.A., Watkins 3rd., J.B., 2003. Diabetes, oxidative stress, and antioxidants: a review. J. Biochem. Mol. Toxicol. 17, 24-38.

McIntosh, C.H.S., Pederson, R.A., 1999. Noninsulin-dependent animal models of diabetes mellitus. In: McNeill, J.H. (Ed.), Experimental Models of Diabetes. CRC Press, Boca Raton, FL, pp. 337-398.

Meinhardt, A., Wilhelm, B., Seitz, J., 1999. Expression of mitochondrial marker proteins during spermatogenesis. Hum. Reprod. Update 5, 108-119.

Moreira, P.I., Santos, M.S., Moreno, A.M., Proença, T., Seiça, R., Oliveira, S.R., 2004. Effects of streptozotocin-induced diabetes on rat brain mitochondria. J. Endocrinol. 16, 32-38.

Moreira, P.I., Santos, M.S., Sena, C., Seiça, R., Oliveira, C.R., 2005. Insulin protects against amyloid B-peptide toxicity in brain mitochondria of diabetic rats. Neurobiol. Dis. 18, 628-637.

Moreira, P.I., Rolo, A.P., Sena, C., Seiça, R., Oliveira, C.R., Santos, M.S., 2006. Insulin attenuates diabetes-related mitochondrial alterations: a comparative study. Med. Chem. 2, 299-308.

Musicki, B., Burnett, A.L., 2007. Endothelial dysfunction in diabetic erectile dysfunction. Int. J. Impot. Res. 19, 129-138.

Nakada, K., Sato, A., Yoshida, K., Morita, T., Tanaka, H., Inoue, S., Yonekawa, H., Hayashi, J., 2006. Mitochondria-related male infertility. Proc. Natl. Acad. Sci. USA 103, 15148-15153.

Newmeyer, D.D., Ferguson-Miller, S., 2003. Mitochondria: releasing power for life and unleashing the machineries of death. Cell 112, 481-490.

Oliveira, P.J., Rolo, A.P., Seiça, R., Palmeira, C.M., Santos, M.S., Moreno, A.J., 2001. Decreased susceptibility of heart mitochondria from diabetic GK rats to mitochondrial permeability transition induced by calcium phosphate. Biosci. Rep. 21, 45-53.

Oliveira, P.J., Seiça, R., Coxito, P.M., Rolo, A.P., Palmeira, C.M., Santos, M.S., Moreno, A.J., 2003. Enhanced permeability transition explains the reduced calcium uptake in cardiac mitochondria from streptozotocin-induced diabetic rats. FEBS Lett. 554 (3), 511-514.

Oliveira, P.J., Seiça, R., Santos, D.L., Rolo, A.P., Sardao, V.A., Ferreira, F.M., Palmeira, C.M., Santos, M.S., Moreno, A.J., 2004. Vitamin E or coenzyme Q10 administration is not fully advantageous for heart mitochondrial function in diabetic goto kakizaki rats. Mitochondrion 3, 337-345.

Oliveira, P.J., Wallace, K.B., 2006. Depletion of adenine nucleotide translocator protein in heart mitochondria from doxorubicin - treated rats - relevance for mitochondrial dysfunction. Toxicology 220, 160-168.

Palmeira, C.M., Madeira, V.M.C., 1997. Mercuric chloride toxicity in rat liver mitochondria and isolated hepatocytes. Environ. Toxicol. Pharmacol. 3, 229235.

Palmeira, C.M., Santos, D.L., Seiça, R., Moreno, A.J., Santos, M.S., 2001. Enhanced mitochondrial testicular antioxidant capacity in goto-kakizaki diabetic rats: role of coenzyme Q. Am. J. Physiol. Cell Physiol. 281 (3), C1023-C1028

Rajdev, S., Reynolds, I.J., 1993. Calcium green-5 N, a novel fluorescent probe for monitoring high intracelular free $\mathrm{Ca}^{2+}$ concentration associated with glutamate exocitoxicity in cultured brain neurons. Neurosci. Lett. 162, 149-152. 
50

S. Amaral et al./ Mitochondrion 9 (2009) 41-50

Rehman, K., Beshay, E., Carrier, S., 2001. Diabetes and male sexual function. J. Sex. Reprod. Med. 1, 29-33.

Rodrigues, B., Poucheret, P., Battell, M.L., McNeill, J.H., 1999. Streptozotocininduced diabetes: induction, mechanisms(s), and dose dependency. In: McNeill, J.H. (Ed.), Experimental Models of Diabetes. CRC Press, Boca Raton, FL, pp. 3-17.

Rolo, A.P., Palmeira, C.M., 2006. Diabetes and mitochondrial function: role of hyperglycemia and oxidative stress. Toxicol. Appl. Pharmacol. 212, 167-178.

Sacarano, W.R., Messias, A.G., Oliva, S.U., Klinefelter, G.R., Kempinas, W.G., 2006. Sexual behaviour, sperm quantity and quality after shortterm streptozotocininduced hyperglycaemia in rats. Int. J. Androl. 29, 482-488.

Said, T.M., Paasch, U., Glander, H.J., Agarwal, A., 2004. Role of caspases in male infertility. Hum. Reprod. Update 10, 39-51.

Scheffler, I.E., 2001. A century of mitochondrial research: achievements and perspectives. Mitochondrion 1, 3-31.

Sexton, W.J., Jarow, J.P., 1997. Effect of diabetes mellitus upon male reproductive function. Urology 49, 508-513.

Silink, M., 2002. Childhood diabetes: a global perspective. Horm. Res. 57, 1-5.

Soudamani, S., Malini, T., Balasubramanian, K., 2005. Effects of streptozotocindiabetes and insulin replacement on the epididymis of prepubertal rats: histological and histomorphometric studies. Endocrinol. Res. 31, 81-98.

Tuomi, T., 2005. Types 1 and 2 diabetes. What do they have in common? Diabetes 54 (Suppl. 2), S40-S45.
Teodoro, J., Rolo, A.P., Oliveira, P.J., Palmeira, C.M., 2006. Decreased ANT content in Zucker fatty rats: relevance for altered hepatic mitochondrial bioenergetics in steatosis. FEBS Lett. 580, 2153-2157.

Vatassery, G.T., Morley, J.E., Kuskowski, M.A., 1983. Vitamin E in plasma and platelets of human diabetic patients and control subjects. Am. J. Clin. Nutr. 37, 641-644.

Walter, L., Nogueira, V., Leverve, X., Heitz, M.P., Bernardi, P., Fontaine, E., 2000. Three classes of ubiquinone analogs regulate the mitochondrial permeability transition pore through a common site. J. Biol. Chem. 275, 29521-29527.

Wei, Y.H., Kao, S.H., 2000. Mitochondrial DNA mutation and depletion are associated with decline of fertility and motility of human sperm. Zool. Stud. $39,1-12$.

Wiernsperger, N.F., 2003. Oxidative stress as a therapeutic target in diabetes: revisiting the control. Diabetes Metab. 29, 579-585.

World Health Organization, 2002. Diabetes: the cost of diabetes (Fact sheet No. 236).

Yu, T., Robotham, J.L., Yoon, Y., 2006. Increased production of reactive oxygen species in hyperglycemic conditions requires dynamic change of mitochondrial morphology. Proc. Natl. Acad. Sci. USA 103, 2653-2658.

Zhou, M., Diwu, Z., Panchuk-Voloshina, N., Haugland, R.P., 1997. A stable nonfluorescent derivative of resorufin for the fluorometric determination of trace hydrogen peroxide: applications in detecting the activity of phagocyte NADPH oxidase and other oxidases. Anal. Biochem. 253, 162-168. 